\title{
FORMATION OF FLAT-TOP PICOSECOND PUMP PULSES FOR OPCPA SYSTEMS BY CASCADE SECOND HARMONIC GENERATION
}

\author{
J. Adamonis ${ }^{\text {a,b }}$, R. Antipenkov ${ }^{\text {a }}$, J. Kolenda ${ }^{\text {b,c }}$, A. Michailovas ${ }^{\text {b, }}$, A.P. Piskarskas ${ }^{\text {a }}$, \\ A. Varanavičius ${ }^{\text {a }}$, and A. Zaukevičius ${ }^{a}$ \\ ${ }^{a}$ Department of Quantum Electronics, Faculty of Physics, Vilnius University, Sauletekio 9, LT-10222 Vilnius, Lithuania \\ ${ }^{\mathrm{b}}$ UAB Ekspla, Savanoriu 231, LT-02300 Vilnius, Lithuania \\ E-mail: j.adamonis@ekspla.com \\ 'Institute of Physics, Center for Physical Sciences and Technology, Savanoriu 231, LT-02300 Vilnius, Lithuania
}

Received 25 May 2012; revised 30 August 2012; accepted 20 September 2012

\begin{abstract}
We report on the method for picosecond pulse envelope shaping that is based on pulse temporal profile transformations during the cascade second harmonic generation. It was demonstrated theoretically and experimentally that under a particular second harmonic generation condition, e. g. pump pulse intensity and crystal length, the $1064 \mathrm{~nm}$ pump pulses with a temporal profile close to the Gaussian one and pulse width of $75 \mathrm{ps}$ at FWHM can be converted to pulses of fundamental and second harmonics with the super-Gaussian temporal profile having an intensity plateau region extending over a $\sim 100$ ps time interval when conversion efficiency in the first stage of the harmonic generator was around $45-50 \%$. Our proposed shaping method is particularly suitable for the application in the multistage OPCPA pumped by the second harmonic of Nd:YAG laser radiation.
\end{abstract}

Keywords: OPCPA, pulse shaping, second harmonic generation

PACS: 42.65.Yj, 42.65.Re, 42.65.Ky

\section{Introduction}

Since its invention in the early 1990 [1] the optical parametric chirped-pulse amplification (OPCPA) has become an attractive alternative to Ti:sapphirebased amplifier systems and has opened up a new path towards generation of high peak power fewcycle pulses [2, 3]. OPCPA systems based on noncollinear parametric amplification provides amplification bandwidths sufficient for the formation of sub-10 fs pulses with peak powers of terawatt level [4. 5]; however, both total gain and gain spectral bandwidth sensitively depend on the temporal and spatial shape of the pump pulses [6]. In most cases a pump pulse with a Gaussian temporal profile is used. If a uniform gain across spectral signal bandwidth is to be achieved, the pump pulse has to be significantly longer than the seed pulse in order to keep pump intensity approximately constant during amplification. In this case, however, a large fraction of pump energy is discarded, thereby lowering the overall efficiency of the parametric amplification process. If the seed and pump pulses are of comparable duration, the gain along the chirped seed pulse is non-uniform and usually leads to the narrowing of the amplified pulse spectrum. The pump pulses with a rectangular temporal profile and duration comparable to that of the seed pulse would provide a uniform gain for all seed spectral components, thereby avoiding spectral gain narrowing, increasing pump-to-signal conversion efficiency [7], and improving the amplified pulse contrast ratio in respect to parametric superfluorescence background [8]. There are numbers of techniques for the shaping of nanosecond or femtosecond pulses. The formation of flat-top temporal profile pulses on a nanosecond scale are mostly based on the application of fast optoelectronics [7] 9. 10] while the temporal shape of the femtosecond or sub-picosecond pulse can be modified by 
amplitude and phase modulation of the pulse spectral components employing the spatial light modulator [11-14] or acousto-optic programmable dispersive filter [15-17]. For the pulses of 30-100 ps duration the application of these methods is rather limited due to a narrow pulse spectrum (fractions of nanometer) and insufficient temporal resolution of optoelectronic schemes. It was demonstrated that the picosecond pulse envelope could be shaped by pulse stacking [18-21]. However, the resultant pulse shape obtained using this method is extremely sensitive to mechanical and thermal perturbations on an interferometric scale.

In this work we introduce a method for picosecond pulse envelope shaping that is based on pulse temporal profile transformations during cascade second harmonic generation. The main idea of pulse formation could be presented as follows. In a second harmonic generation process the temporal profile of the fundamental harmonic (FH) pulse undergoes significant changes governed by the input pulse temporal profile and frequency conversion efficiency. In case of pulses with the Gaussian temporal profile and negligible group velocity mismatch of the interacting pulses the growth of energy conversion to the second harmonic ( $\mathrm{SH}$ ) leads to the flattening of residual fundamental pulse envelope and consequent formation of a dip in the temporal pulse profile [22, 23. The modified fundamental pulse leaving the first second harmonic generator could be used as a pump pulse in the second stage of the harmonic generator. The SH generator pumped by flat-top pulses will produce flat-top pulses of the second harmonic as well. In this paper we present numerical simulations revealing the possibilities to shape picosecond pulses using tandem second harmonic generators and report experimental results on the formation of a 100-150 ps flat-top pulse at $532 \mathrm{~nm}$ that could be used for the efficient pumping of OPCPA systems.

\section{Computer simulations}

In order to find out the conditions for effective pulse envelope transformations employing cascade $\mathrm{SH}$ generators we performed a numerical simulation of the three-wave parametric interaction using the symmetrised split-step method [24, 25]. Ac- cording to the model the nonlinear crystal was divided into a number of slices. Diffraction and material dispersion were accounted for in each slice independently from the nonlinearity of material. The linear propagation of the waves was handled in the Fourier space as [26]:

$$
\begin{aligned}
& A_{j}(t, x, y, z+\Delta z)=F^{-1}\left\{S_{j}\left(\omega, k_{x}, k_{y}, z\right)\right. \\
& \left.x \exp \left(-i \sqrt{k\left(\omega, k_{x}\right)^{2}-k_{x}^{2}-k_{y}^{2} \Delta z}\right)\right\},
\end{aligned}
$$

where $j=1$ and 2 indicate a fundamental and a second harmonic, respectively, $F^{-1}$ denotes the inverse Fourier transformation, and $S_{j}\left(\omega, k_{x}, k_{y}, z\right)$ is the initial spectrum of the wave given by $S_{j}\left(\omega, k_{x}, k_{y}, z\right)=$ $F\left\{A_{j}(t, x, y, z)\right\}$. Dispersion and diffraction effects were accounted for via exponential term in Eq. (1), where $k(\omega)$ describes the material dispersion. For the extraordinary wave the spatial walk-off was taken into account via $k$ dependence on $k_{x}$, i. e. on propagation direction. The computation of nonlinear propagation of the waves was performed using the fourth-order Runge-Kutta method for integration of the coupled wave equations (2), (3) in the near field representation $(t, x, y, z)$ :

$$
\begin{aligned}
& \frac{\partial A_{1}}{\partial z}=-\mathrm{i} \frac{\omega_{1}^{2}}{k_{1} c^{2}} d_{\mathrm{eff}} A_{2} A_{1}^{*}, \\
& \frac{\partial A_{2}}{\partial z}=-\mathrm{i} \frac{\omega_{2}^{2}}{2 k_{2} c^{2}} d_{\mathrm{eff}} A_{1}^{2} .
\end{aligned}
$$

Numerical simulations were performed for the case of two-stage cascaded SH generation employing a type-I (oo-e) phase matching DKDP crystals with a length $L=10 \mathrm{~mm}$ in the first stage and $L=20 \mathrm{~mm}$ in the second stage of the SH generator. The coefficients of Sellmeier equations given by Lozhkarev et al. [27] were used and the effective second-order nonlinear susceptibility was taken to be $d_{\text {eff }}=0.22 \mathrm{pm} / \mathrm{V}$. It was assumed that the $\mathrm{FH}$ pump pulse entering the SH generators has a Gaussian temporal profile with the pulsewidth at FWHM of 70 ps and a third-order super Gaussian spatial profile with the full-width at the half maximum (FWHM) of $7.5 \mathrm{~mm}$ that was the best fit for the experimentally obtained $\mathrm{FH}$ beam profile.

Figure 1 presents the simulated FF pulse temporal profiles on the beam axis. It shows that changes in the temporal profile of the residual $\mathrm{FH}$ after the 
first stage of SH generation when increasing pump pulse intensity $I_{\mathrm{p}}$ are quite substantial. At a pump intensity value of $I_{\mathrm{p}}=4 \mathrm{GW} / \mathrm{cm}^{2}$ the $\mathrm{FH}$ pulse envelope takes a flat-top temporal profile exhibiting the pulse intensity plateau region of $\approx 50 \mathrm{ps}$ (line (2) in Fig. 1(a)). Note that in this case the FWHM pulse duration increases up to 111 ps. Further increase of pump intensity results in progressively growing envelope modulation of the FH pulse (see lines (3), (4) in Fig. 1(a)).

In the second step we performed the computer simulation of the $\mathrm{SH}$ generation using the funda-
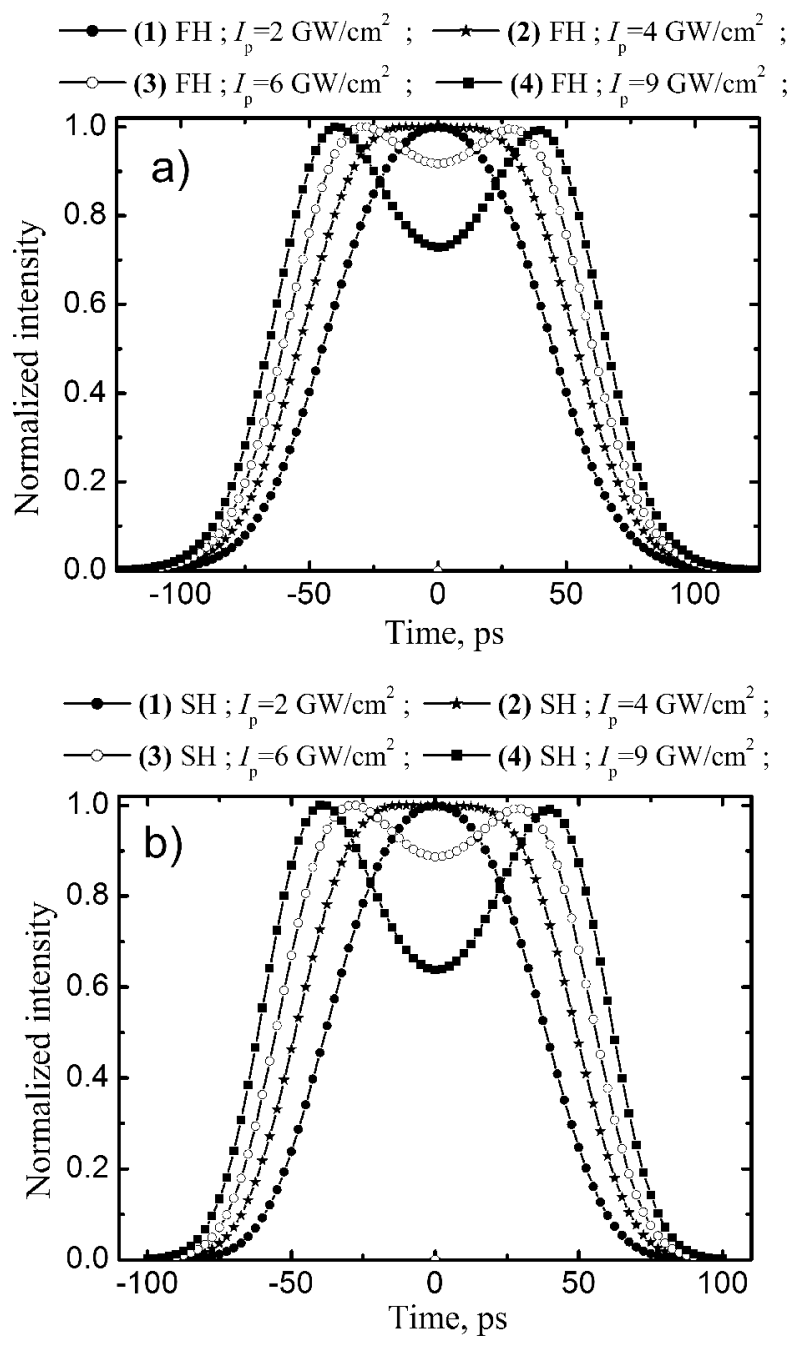

Fig. 1. Simulated FF pulse temporal profiles on the beam axis of (a) FH and (b) SH pulses after the first stage of the SH generator for different pump pulse peak intensities. $I_{\mathrm{p}}$ is pump peak intensity at the first stage of the $\mathrm{SH}$ generator. mental harmonic pulses depicted in Fig. 1(a) as a pump for the second stage of the $\mathrm{SH}$ generator. The simulation results presented in Fig. 1(b) show that the temporal profile of the SH pulse generated in the second stage tends to repeat the pump pulse temporal profile with modestly reduced pulse duration and increased temporal modulation. Also it is worth to mention that using the same approach and more than two $\mathrm{SH}$ generation stages the $\mathrm{FH}$ and the $\mathrm{SH}$ pulse flattening effect become more and more notable after each subsequent $\mathrm{SH}$ generation stage and the shape of the pulse envelope approaches the rectangular one.

The pulses exhibiting an intensity dip in their temporal profile could also find an application as a pump for OPCPA systems, providing an opportunity to achieve a higher gain for the spectral component situated at the leading and trailing edges of the seed pulse and obtain a broader amplified pulse spectrum. Another possibility to control the $\mathrm{FH}$ pulse shape is to generate the $\mathrm{SH}$ pulses at a slight detuning $\Delta \theta$ from the angle of perfect phase-matching [28, 29]. As can be seen from Fig. 2(b), the flat-top shape of the FH pulse envelope with some ripples on the top of the pulses can be realised at pump intensity of $I_{\mathrm{p}}=9 \mathrm{GW} / \mathrm{cm}^{2}$ and $\Delta \theta=0.12 \mathrm{mrad}$ when using $10 \mathrm{~mm}$ long DKDP crystal. This option is more favourable for achieving higher energy conversion to the SH. However, the operation of $\mathrm{SH}$ stages in high energy conversion regimes is rather critical to the $\mathrm{SH}$ crystal angular adjustment. As shown in Fig. 2(b) at pump intensity $I_{\mathrm{p}}=9 \mathrm{GW} / \mathrm{cm}^{2}$ the slight detuning of $\mathrm{SH}$ crystal from perfect phase-matching leads to significant perturbations in the shape of a residual $\mathrm{FH}$ pulse, while at $I_{\mathrm{p}}=4 \mathrm{GW} / \mathrm{cm}^{2}$ the changes of the pulse temporal profile are significantly less pronounced (see Fig. 2(a)).

\section{Experimental set-up}

The experiment was carried out using the Nd:YAG based amplification system developed for the pumping of OPCPA set up at Vilnius University. The key feature of our laser and measurement system is the direct seeding of picosecond (ps) Nd:YAG amplifiers by femtosecond (fs) pulses from the Yb:KGW oscillator which in parallel is used as a seed source for a femtosecond $\mathrm{Yb}$ :KGW regenerative amplifier. Such approach ensured reliable full-optical fs-ps 
pulse synchronisation of the whole laser system and allowed for the measurement of the temporal profile of picosecond pulses by probing them with femtosecond ones.

In our set-up schematically presented in Fig. 3the $\mathrm{Yb}: \mathrm{KGW}$ fs oscillator (Light Conversion, $L t d$.) which provides pulses of $60 \mathrm{fs}$ duration and of $9 \mathrm{~nJ}$ energy at a $78 \mathrm{Mhz}$ repetition rate was used as a seed source both for femtosecond Yb:KGW regenerative amplifiers and for the picosecdond Nd:YAG amplification system.

The Yb:KGW amplifier and Nd:YAG amplifier operate at different wavelengths, namely 1030

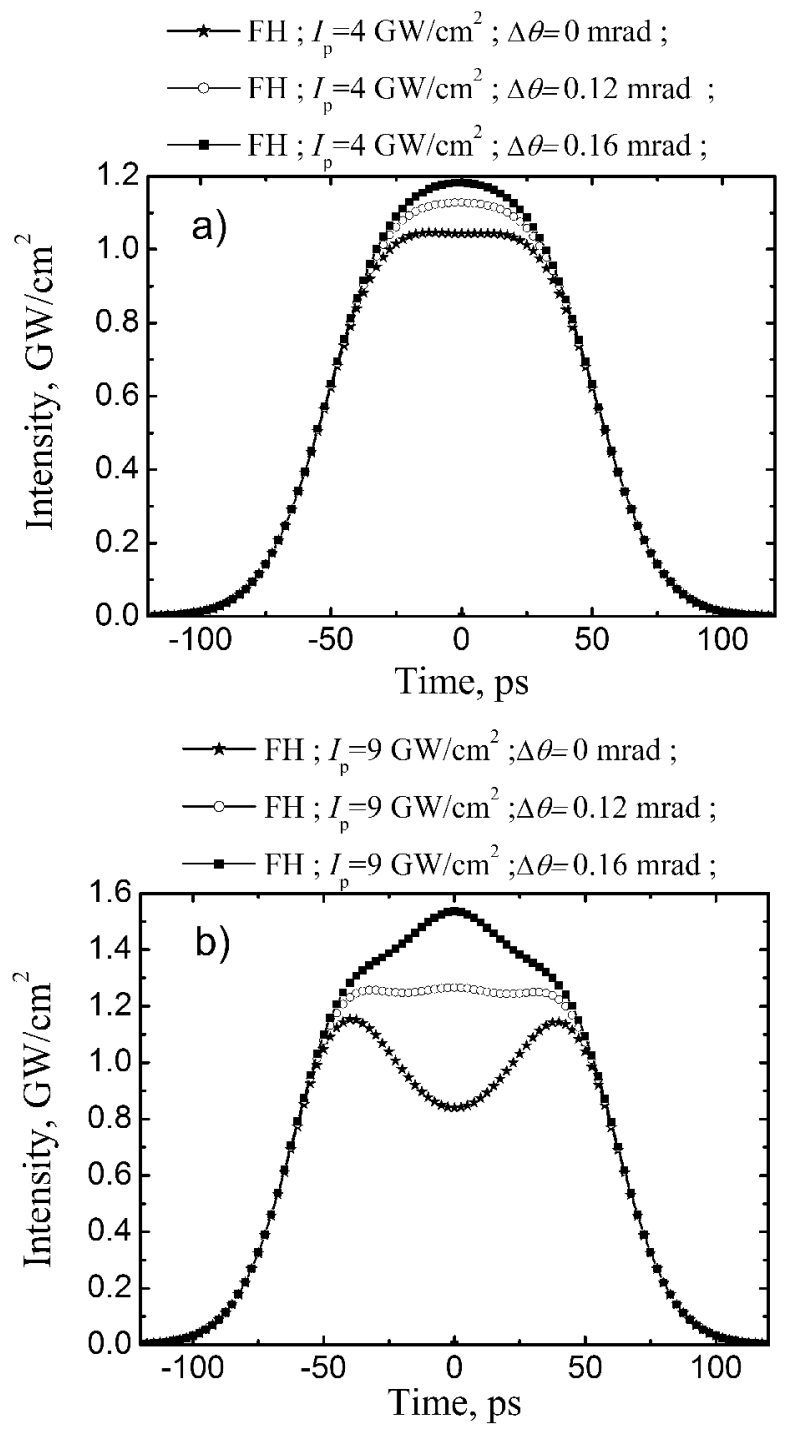

Fig. 2. Simulated temporal profiles of the residual of the FH pulse at pump intensity (a) $I_{\mathrm{p}}=4 \mathrm{GW} / \mathrm{cm}^{2}$ and (b) $I_{\mathrm{p}}=9 \mathrm{GW} / \mathrm{cm}^{2}$ for different detuning angles $\Delta \Theta$ of the SH crystal. and $1064 \mathrm{~nm}$. The output pulses from the oscillator are spectrally divided into two parts using a spectrally selective beam splitter composed of a custom design phase retardation quartz plate $\lambda / 2$ and a polarisation cube PC. The phase retardation plate preserves polarisation direction of a $1064 \mathrm{~nm}$ spectral component and rotates by 90 deg the polarisation plane of the oscillator pulse spectral components in the vicinity of $1030 \mathrm{~nm}$. The 1030 and $1064 \mathrm{~nm}$ spectral components are separated by the polarisation cube and directed to the inputs of $\mathrm{Yb}: \mathrm{KGW}$ and Nd:YAG amplifiers. The Yb:KGW amplifier (PHAROS, Light Conversion, Ltd.) is a diode pumped chirped pulse regenerative amplifier delivering $\sim 300 \mathrm{fs}$ pulses with a maximum energy of $450 \mu \mathrm{J}$ at $1 \mathrm{kHz}$ repetition rate. The Nd:YAG amplification system (Ekspla $U A B$ ) was specially designed for delivering high energy picosecond pulses for the pumping of the OPCPA system. It comprises the tandem diode pumped Nd:YAG regenerative amplifiers and a flash lamp pumped Nd:YAG power amplifier. The femtosecond seed pulse after amplification system was stretched in time up to $\sim 75$ ps duration due to gain narrowing in the Nd:YAG laser media and due to the spectral filtering effect of multiple intracavity FabryPerot etalons placed inside regenerative amplifier cavities (for details see [30]). The Nd:YAG power amplifier boosted pulse energy up to $500 \mathrm{~mJ}$ at a repetition rate of $10 \mathrm{~Hz}$. The spatial shape of the output beam had smooth intensity distribution (see inset in Fig. 3) which was well approximated by a third-order super Gausian function with FWHM of $7.5 \mathrm{~mm}$.

In the experiment the DKDP crystals of 10 or $13 \mathrm{~mm}$ in length were used in the first stage of the $\mathrm{SH}$ generator, while the length of the crystal in the second stage was $20 \mathrm{~mm}$. All the crystals were cur for type I phase matching at polar angle $\theta=36.6^{\circ}$ and azimuthal angle $\phi=45^{\circ}$. The measurements of the temporal shape of FH pulses were performed by using a third-order cross-correlator (Sequoia, Amplitude Technologies) designed for a 1000-1150 nm wavelength range. In this crosscorrelator the third harmonic generation is employed to achieve cross-correlation between the incident pulse and the probe pulse. In standard configuration the probe pulse is the $\mathrm{SH}$ of the pulse itself. For our experiments we modified the arrangement of a cross-correlator by setting up an 


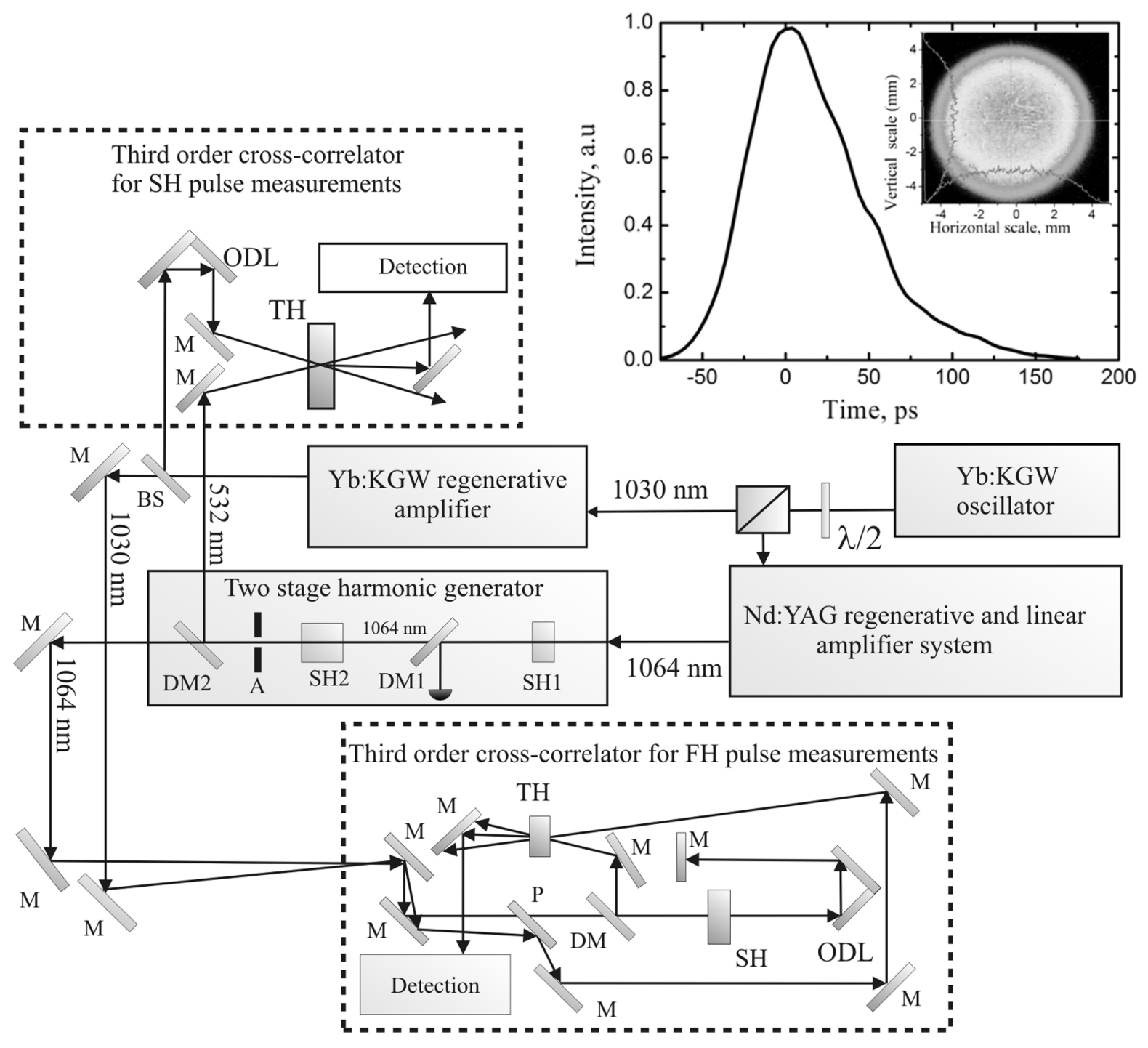

Fig. 3. Picosecond pulse shaping and measurement system: $M$ mirrors, $O D L$ optical delay line, $S H 1$ DKDP crystal (10 or $13 \mathrm{~mm}$ long), SH2 DKDP crystal $20 \mathrm{~mm}$ long, $S H$ and TH second and third harmonic crystals for pulse crosscorrelation measurements, respectively, $D M$ dichroic mirrors, $A$ aperture, $P C$ polarisation cube. Inset shows the $\mathrm{FH}$ pulse temporal profile and beam intensity spatial distribution at the output of Nd:YAG amplifiers.

additional beam path for femtosecond pulses delivered by the PHAROS system and using the $\mathrm{SH}$ of these pulses as a probe. The probe pulse duration was more than 100 times shorter than the duration of picosecond pulses and the evolution of the third harmonic signal with respect to the time delay between incident and probe pulses gave an accurate representation of the picosecond pulse temporal profile. The measurement of the temporal shape of local intensity was performed using an aperture which selected the small area of picosecond pulse beam cross-section. amplifier system 


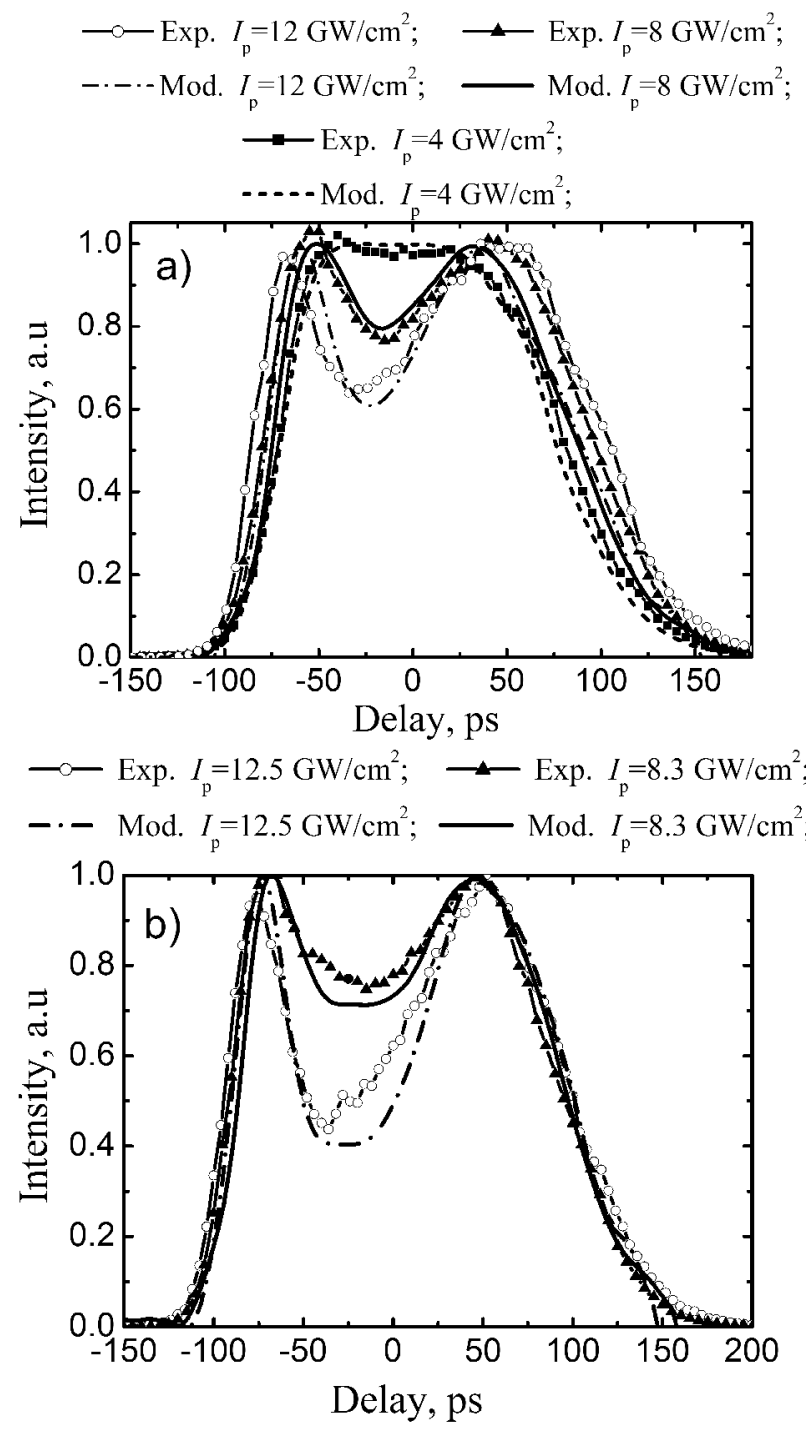

Fig. 4. Temporal profile of a residual FH pulse in the beam centre at different pump intensities for (a) 10 and (b) $13 \mathrm{~mm}$ long DKDP crystals. Circles, triangles and squares represent experimental data; lines show results of numerical modelling.

pulse takes place and at a certain pump intensity level the pulse envelope of the residual FH becomes flat-top shaped. Further increase of pump intensity and corresponding conversion efficiency to the $\mathrm{SH}$ leads to the appearance of a dip in the pulse temporal envelope. The measured pulse temporal profiles were in good agreement with the results of computer simulations performed using actual pump pulse characteristics.

It is evident that pulse shape changes in the $\mathrm{FH}$ beam are spatially dependent as pump intensity varies across the beam. This variation should be taken into account when exploiting the pulse temporal profile modifications in real application of OPCPA. In Fig. 5 the results of pulse shape measurements performed by acquiring the signal from the whole beam are presented. One can see that in this case both pulse flattening and pulse envelope modulation effects are less pronounced as compared to the results of the pulse envelope measurements at the same pulse peak intensity in the beam centre (see Fig. 4). The efficiency of the $\mathrm{SH}$ generation and, consequently, FH pulse shape modification in the peripheral areas of the beam is much weaker due to lower pulse intensity values. The contributions from these areas to an integral pulse envelope noticeably conceal the pulse shape transformations taking place in the central part of the beam. Therefore, the flat-top temporal profile of the total pulse power (Fig. 5(b)) was observed at nearly two times higher peak intensity as compared to the intensity required to flatten the residual $\mathrm{FH}$ pulse in the beam centre (see Fig. 4(a)). The results of computer simulation performed by integrating pulse shape modifications across the whole beam (dotted lines in Fig. 5) differ somewhat from the experimental data. We suspect that this discrepancy arises due to the high degree of thermo-optical distortion, i. e. due to depolarisation which changes the initial state of beam polarisation significantly near the surface of the flash lamp pumped cylindrical Nd:YAG rod (12 $\mathrm{mm}$ diameter) of the last amplification stage. This results in a considerably reduced efficiency of frequency conversion from peripheral beam areas in the crystals of a third-order cross-correlator thus affecting the shape of the measured temporal profile of the total pulse power. Results of $\mathrm{FH}$ pulse temporal profile simulations obtained after the integration diameter is artificially reduced to $9 \mathrm{~mm}$ (dashed lines in Fig. 5) approach the measured pulse temporal profile, which supports the abovepresented argumentation.

In order to estimate quantitatively the temporal pulse shape flattening effect at different experimental conditions we introduced the "pulse shape factor" (PSF) and defined it as: $\mathrm{PCF}=E_{\mathrm{f}} / E_{\mathrm{t}}$, where $E_{\mathrm{f}}$ is the calculated amount of pulse energy contained under the pulse envelope within intensity limits of $(0.9-1) I_{\max }$, and $E_{\mathrm{t}}$ is the total pulse energy. The values of this factor for Gaussian and rectangular pulses are 0.35 and 1 , respectively. We found that in our experimental conditions the gradual increase 

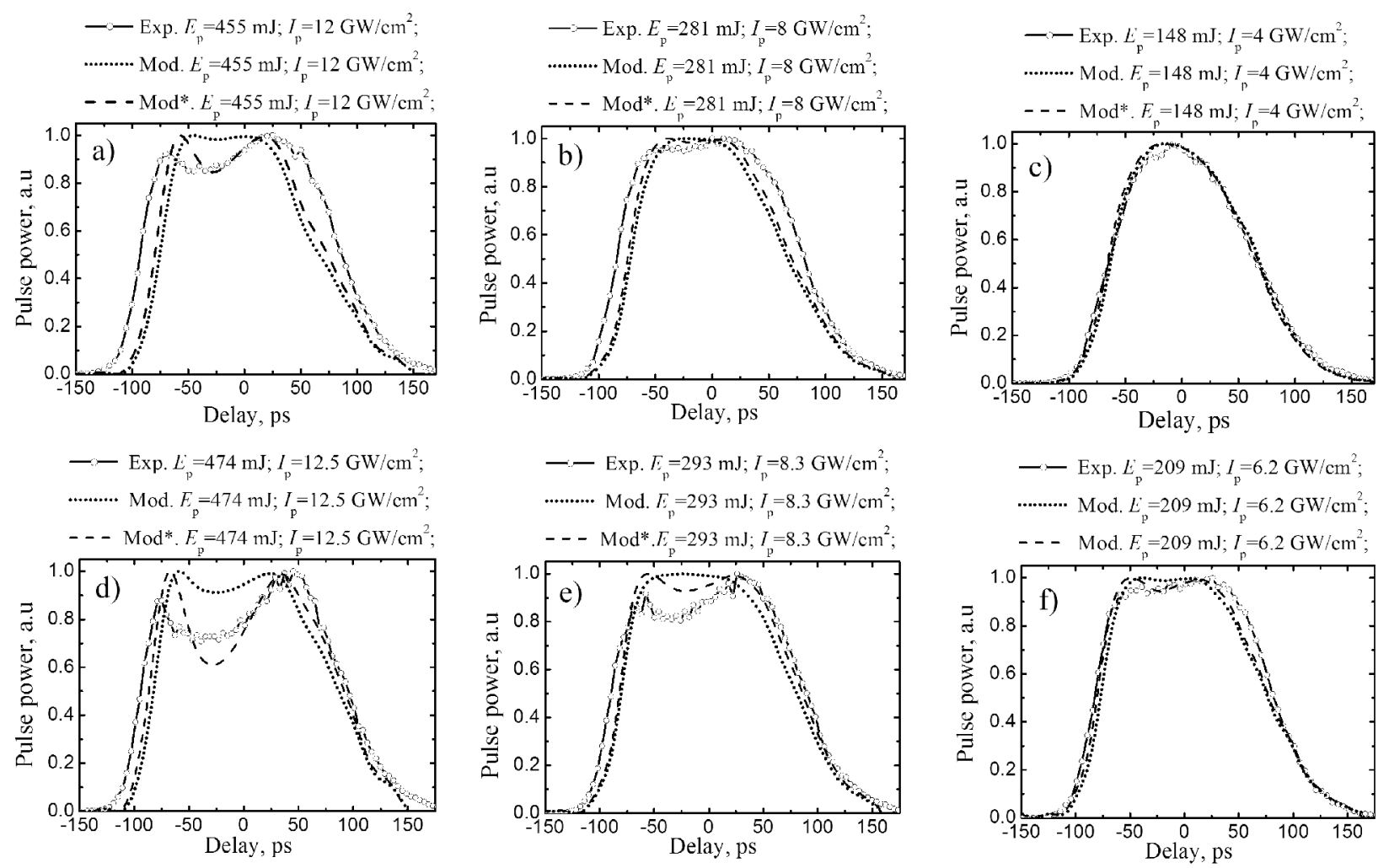

Fig. 5. Temporal profiles of FH pulse power after the first stage of the SH generator for the crystal lengths of (a-c) 10 and $(\mathrm{d}-\mathrm{f}) 13 \mathrm{~mm}$ at different pump peak intensities $I_{\mathrm{p}}$ and pump pulse energies. Circles are experimental data. Dotted and dashed lines represent the results of simulation obtained by integrating the data from the beam area enclosed by a circle of 12 and $9 \mathrm{~mm}$ in diameter, respectively.

of pump intensity results in the rise of the PSF value from the starting value of 0.3 to approx. 0.64 when conversion efficiency $\eta_{1}$ to the $\mathrm{SH}$ reaches the level of $\sim 45 \%$. The obtained results were roughly the same for the DKDP crystal length of both 10 and $13 \mathrm{~mm}$. The only difference was that the maximum pulse temporal profile flattening for the crystal of $13 \mathrm{~mm}$ was recorded at a $\sim 25 \%$ lower pump pulse energy. So, the flat-top pulse was generated using a nonlinear crystal of different length and attaining 45-50\% pump to the SH conversion efficiency by adjusting pump pulse intensity. A further increase of conversion efficiency to the SH results in the noticeable modulation of the pulse temporal profile and sharp drop of the PSF value.

The flat-top second harmonic pulses at $532 \mathrm{~nm}$ were obtained in the second stage of the SH generator (see Fig. 3). The energy conversion efficiency $\eta_{2}$ to the $\mathrm{SH}$ in a $20 \mathrm{~mm}$ long DKDP crystal was in the range of $20-40 \%$ depending on the pump pulse energy. The temporal structure of the ps second har- monic pulses generated in the second SHG stage was characterised by a custom-made third-order cross-correlator in which $1030 \mathrm{~nm}$ femtosecond pulses from the PHAROS system were used for the $532 \mathrm{~nm}$ picosecond pulse probing (see Fig. 3). The SH pulse temporal profiles measured for different FH pulse intensities $I_{\mathrm{p}}$ at the entrance of a two-stage SH generator are presented in Fig. 6. Similar to the results of computer simulations presented in Section 1 , in the case of flat-top pump pulses both the SH pulse duration and the width of the intensity plateau correspond to those of the pump pulse with the accuracy of $<5 \%$. The slight difference between the cases of 10 and $13 \mathrm{~mm}$ long crystals in the first SH stage can be explained by different saturation of the second $\mathrm{SH}$ stage. For the case of higher conversion efficiency in the first $\mathrm{SH}$ generation stage the pump pulse modulation is transferred to the $\mathrm{SH}$ pulse temporal profile with certain increase in the magnitude of this modulation. We should note, however, that due to the difference in the $\mathrm{SH}$ generation 

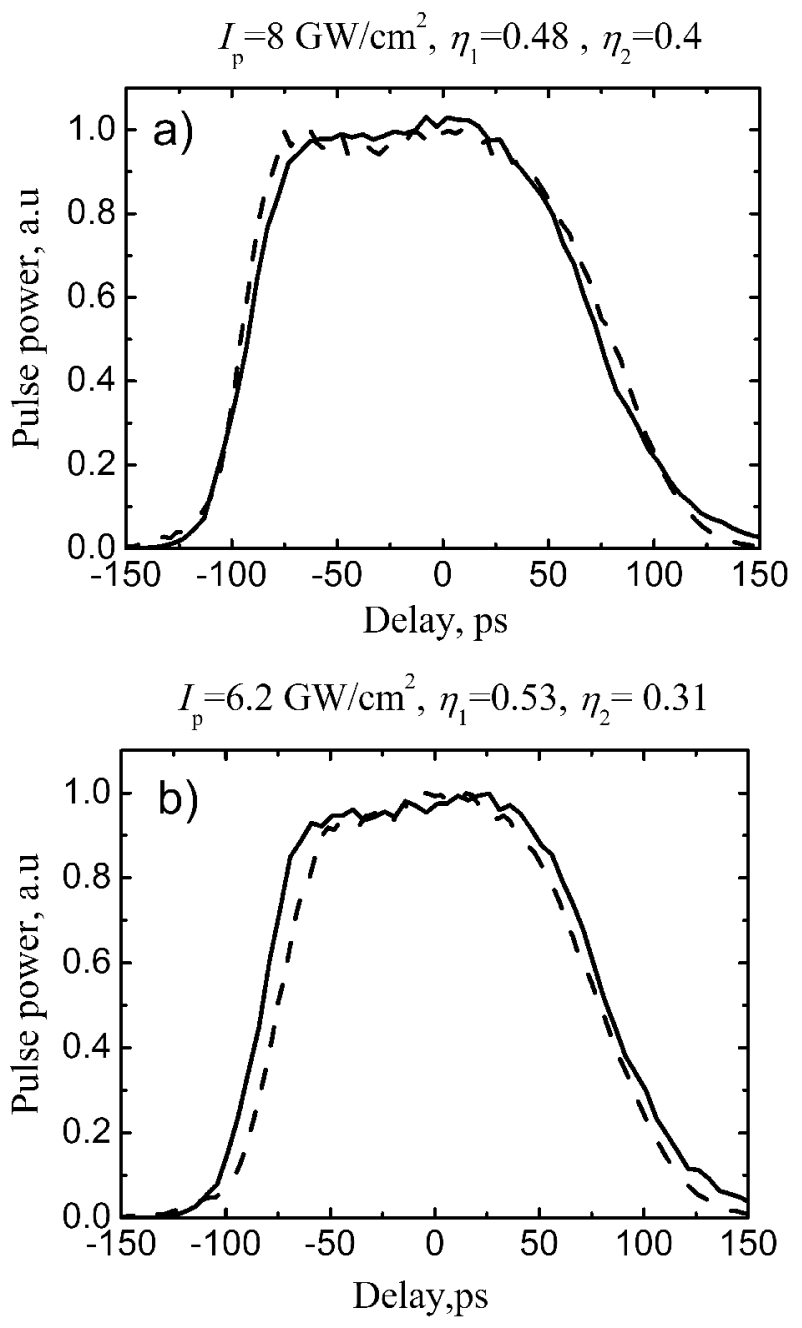

Fig. 6. Flat-top pulses from a cascade $\mathrm{SH}$ generator using (a) 10 and (b) $13 \mathrm{~mm}$ long crystals in the first $\mathrm{SH}$ generation stage: solid lines represent the temporal profile of $\mathrm{FH}$ pulses, dashed lines represent the temporal profile of $\mathrm{SH}$ pulses, $\eta_{1}$ and $\eta_{2}$ indicate the conversion efficiency in the first and second stage of the SH generator, respectively.

efficiency across the beam, the $532 \mathrm{~nm}$ pulse shape is a function of transverse space coordinate. For example, in case when the integral SH pulse envelope features nearly a flat-top profile (dashed lines in Fig. 6) the pulse envelope measured transmitting only the central part of the $\mathrm{SH}$ beam (aperture size $1.5 \mathrm{~mm}$ ) exhibits an $8 \%$ intensity drop at the pulse centre. The pulse envelope shape dependence on the spatial position in the beam cross-section can be minimised using beams with a high-order super-Gaussian spatial profile.

\section{Conclusions and outlook}

In this work we present the results of investigations of the picosecond pulse temporal profile modifications taking place in the two-stage $\mathrm{SH}$ generator. We showed that in particular the second harmonic generation conditions the $1064 \mathrm{~nm}$ pump pulses with a temporal profile close to Gaussian and the pulsewidth of $\sim 75$ ps at FWHM can be converted to pulses of a fundamental and second harmonic with the super-Gaussian temporal profile having the intensity plateau region extending over a $\sim 100$ ps time interval. In our experimental conditions the flat-top pulse formation was achieved using a nonlinear crystal of different length and attaining 45$50 \%$ pump to the $\mathrm{SH}$ conversion efficiency in the first stage of the $\mathrm{SH}$ generator.

The proposed shaping method is particularly suitable for the application in the multistage OPCPA pumped by the second harmonic of Nd:YAG lasers. Using this method the residual radiation of the fundamental harmonic after $\mathrm{SH}$ generation in the first stage is effectively used in the second stage of $\mathrm{SH}$ generation for the formation of pump pulses with a sufficiently broad intensity plateau region. The use of such pulses as a pump for high gain OPCPA system stages minimises the effect of seed pulse spectrum narrowing and allows reducing the energy of a parametric superfluorescence signal which deteriorates the final pulse contrast. The SH pulse generated in the first stage retains the Gaussian temporal profile, but still can be efficiently applied as a pump in the last stage of a multistage OPCPA set-up. This stage is usually operated in the regime of a small gain and strong saturation [31, 32] what allows avoiding the amplified pulse spectrum narrowing caused by the Gaussian temporal profile of pump pulses.

\section{Acknowledgments}

This work was partly supported by LASERLABEUROPE III (grant agreement No. 284464, EC's Seventh Framework Programme).

\section{References}

[1] A. Dubietis, G. Jonusauskas, and A. Piskarskas, Powerful femtosecond pulse generation by chirped and stretched pulse parametric amplification in BBO crystal, Opt. Commun. 88, 437-440 (1992). 
[2] I.N. Ross, P. Matousek, G.H.C. New, and K. Osvay, Analysis and optimization of optical parametric chirped pulse amplification, J. Opt. Soc. Am. B 19 (2002).

[3] N. Ishii, L. Turi, V.S. Yakovlev, T. Fuji, F. Krausz, A. Baltuska, R. Butkus, G. Veitas, V. Smilgevicius, R. Danielius, and A. Piskarskas, Multimillijoule chirped parametric amplification of few-cycle pulses, Opt. Lett. 30, 567-569 (2005).

[4] S. Witte, R.Th. Zinkstok, A.L. Wolf, W. Hogervorst, W. Ubachs, and K.S.E. Eikema, A source of 2 terawatt, 2.7 cycle laser pulses based on noncollinear optical parametric chirped pulse amplification, Opt. Express 14, 8168-8177 (2006).

[5] D. Herrmann, L. Veisz, R. Tautz, F. Tavella, K. Schmid, V. Pervak, and F. Krausz, Generation of sub-three-cycle, 16 TW light pulses by using noncollinear optical parametric chirped-pulse amplification, Opt. Lett. 34, 2459-2461 (2009).

[6] V. Pyragaite, A. Stabinis, R. Butkus, R. Antipenkov, and A. Varanavičius, Parametric amplification of chirped optical pulses under pump depletion, Opt. Commun. 283, 1144-1151 (2010).

[7] L.J. Waxer, V. Bagnoud, I.A. Begishev, M.J. Guardalben, J. Puth, and J.D. Zuegel, Highconversion-efficiency optical parametric chirpedpulse amplification system using spatiotemporally shaped pump pulses, Opt. Lett. 28, 1245-1247 (2003).

[8] S. Witte and K. Eikema, Ultrafast optical parametric chirped-pulse amplification, IEEE J. Sel. Topics Quantum Electron. 18, 296-307 (2012).

[9] D.A. Jaroszynski and T.A. King, Subnanosecond pulse generation of $193 \mathrm{~nm}$ radiation by pulse slicing, J. Phys. E: Sci. Instrum. 16, 862-865 (1983).

[10] M.D. Skeldon, A high-bandwidth electrical waveform generator based on an aperture-coupled stripline, Rev. Sci. Instrum. 71, 3559-3566 (2000).

[11]M.M. Wefers and K.A. Nelson, Analysis of programmable ultrashort waveform generation using liquid crystal spatial light modulators, J. Opt. Soc. Am. 12, 1343-1362 (1995).

[12] A.M. Weiner, Femtosecond pulse shaping using spatial light modulators, Rev. Sci. Instrum. 71, 1929-1960 (2000).

[13]J. Kang, W. Zhang, H. Wei, S. Chen, and J. Zhu, Pulse re-shaping by using a liquid crystal spatial light modulator and deflector for producing a specific waveform, Chin. Opt. Lett. 4, 184-186 (2006).

[14] S. Cialdi, F. Castelli, and I. Boscolo, Rectangular pulse formation in a laser harmonic generation, Appl. Phys. B 82, 383-389 (2006).

[15] M.A. Dugan, J.X. Tull, and W.S. Warren, Highresolution acousto-optic shaping of unamplified and amplified femtosecond laser pulses, J. Opt. Soc. Am. 14, 2348-2358 (1997).
[16]D. Kaplan and P. Tournois, Theory and performance of the acousto optic programmable dispersive filter used for femtosecond laser pulse shaping, J. Phys. IV 12, 69-75 (2002).

[17] T. Balčiūnas, G.Y. Fan, G. Andriukaitis, A. Pugžlys, and A. Baltuška, High-power top-hat pulses from a $\mathrm{Yb}$ master oscillator power amplifier for efficient optical parametric amplifier pumping, Opt. Lett. 37, 2547-2549 (2012).

[18] C.E. Thomas and L.D. Siebert, Pulse shape generator for laser fusion, Appl. Opt. 15, 462-465 (1976).

[19]W.E. Martin and D. Milam, Interpulse interference and passive laser pulse shapers, Appl. Opt. 15, 3054-3061 (1976).

[20] C.W. Siders, J.L.W. Siders, A.J. Taylor, S.-G. Park, and A.M. Weiner, Efficient high-energy pulse train generation using a $2 \mathrm{n}$-pulse Michelson interferometer, Appl. Opt. 37, 5302-5305 (1998).

[21]J.A. Fülöp, Zs. Major, B. Horváth, F. Tavella, A. Baltuška, and F. Krausz, Shaping of picosecond pulses for pumping optical parametric amplification, Appl. Phys. B 87, 79-84 (2007).

[22] J.C. Diels and W. Rudolph, Ultrashort Laser Pulse Phenomena (Academic Press Inc., New York, 2006).

[23] A. Dement'ev, V. Girdauskas, O. Vrublevskaja, and R. Kazragyte, Numerical investigation of influence of the nonlinear refraction index upon the second harmonic generation, Lith. J. Phys. 42(4), 263-274 (2002).

[24] G. Arisholm, General numerical methods for simulating second-order nonlinear interactions in birefringent media, J. Opt. Soc. Am. B 14, 25432549 (1997).

[25]S. Witte, R. Zinkstok, W. Hogervorst, and K. Eikema, Numerical simulations for performance optimization of a few-cycle terawatt NOPCPA system, Appl. Phys. B 87, 677-684 (2007).

[26] A. Couairon, E. Brambilla, T. Corti, D. Majus, O. de J. Ramırez-Gongora, and M. Kolesik, Practitioners guide to laser pulse propagation models and simulation, Eur. Phys. J. Spec. Top. 199, 5-76 (2011).

[27] V.V. Lozhkarev, G.I. Freidman, V.N. Ginzburg, E.A. Khazanov, O.V. Palashov, A.M. Sergeev, and I.V. Yakovlev, Study of broadband optical parametric chirped pulse amplification in a DKDP crystal pumped by the second harmonic of a Nd:YLF laser, Laser Phys. 15, 1319-1333 (2005).

[28] C.R. Mendonca, L. Misoguti, and S.C. Zilio, Second harmonic pulse distortion by imperfect phase matching, Opt. Commun. 174, 481-486 (2000).

[29]D. Majus, O. Jedrkiewicz, M. Molteni, P. Ragazzi, P. Di Trapani, and G. Tamošauskas, Spatiotemporal characterization of self-formed hollow light pulses in the pump depletion regime of 
second harmonic generation, Eur. Phys. J. Spec. Top. 199, 77-87 (2011).

[30]J. Adamonis, R. Antipenkov, J. Kolenda, A. Michailovas, A.P. Piskarskas, and A. Varanavičius, High energy Nd:YAG amplifier system for OPCPA pump, Quant. Electron. 42, 567-574 (2012).
[31]V. Bagnoud, I.A. Begishev, M.J. Guardalben, J. Puth, and J.D. Zuegel, $5 \mathrm{~Hz},>250 \mathrm{~mJ}$ optical parametric chirped-pulse amplifier at $1053 \mathrm{~nm}$, Opt. Lett. 30, 1843-1845 (2005).

[32] J. Moses, C. Manzoni, S. Huang, G. Cerullo, and F.X. Kartner, Temporal optimization of ultrabroadband high-energy OPCPA, Opt. Express 17, 5540-5555 (2009).

\title{
PLOKŠČIOS VIRŠŪNĖS PIKOSEKUNDINIŲ KAUPINIMO IMPULSŲ PARAMETRINIO STIPRINIMO SISTEMOMS FORMAVIMAS PAKOPINIAIS ANTROSIOS HARMONIKOS GENERATORIAIS
}

\author{
J. Adamonis ${ }^{\mathrm{a}, \mathrm{b}}, \mathrm{R}$. Antipenkov ${ }^{\mathrm{a}}$, J. Kolenda ${ }^{\mathrm{b}, \mathrm{c}}$, A. Michailovas ${ }^{\mathrm{b}, \mathrm{c}}$, A. P. Piskarskas ${ }^{\mathrm{a}}$, A. Varanavičius ${ }^{\mathrm{a}}$, \\ A. Zaukevičius ${ }^{a}$ \\ ${ }^{a}$ Vilniaus universiteto Fizikos fakulteto Kvantinès elektronikos katedra, Vilnius, Lietuva \\ ${ }^{\mathrm{b}}$ UAB Ekspla, Vilnius, Lietuva \\ ${ }^{\mathrm{c}}$ Fiziniu ir technologijos mokslu centro Fizikos institutas, Vilnius, Lietuva
}

\section{Santrauka}

Darbe pristatome metodą, skirtą formuoti pikosekundinių impulsų gaubtinę, naudojant pakopinius antrosios harmonikos generatorius. Eksperimentiškai ir teoriškai parodyta, kad parinkus atitinkamą kaupinimo impulso intensyvumą bei antrosios harmonikos kristalo ilgi, pirmosios harmonikos $1064 \mathrm{~nm}$ bangos ilgio ir 75 ps trukmès Gauso formos impulsai tribangès są- veikos metu transformuojami i pirmosios ir antrosios harmonikos impulsus, kurių plokščios impulso gaubtinès sritis viršija 100 ps trukmès intervalą, kai keitimas pirmosios pakopos antrosios harmonikos generatoriuje yra 45-50\%. Siūlomas impulsų gaubtinès formavimo metodas gali būti efektyviai taikomas daugiapakopèse moduliuotos fazès impulsų parametrinèse stiprinimo sistemose. 